\title{
Presentación
}

\section{Decolonialidad y educación: epistemologías y experiencias desde el sur global}

\author{
AndrÉs ARgüEllo PARRA* \\ Priscyll AnCtil AVOInE**
}

DOI: $10.31391 / S 2007-7033(2019) 0052-001$

Muchas formas de colonialidad parecen caracterizar la escena social, política, económica y cultural de las sociedades globales. La persistencia colonial no se reduce únicamente a los imperialismos históricos o a la hegemonía del paradigma de la modernidad en su clásica versión racionalista, capitalista e ilustrada. La colonialidad, al igual que el ser aristotélico, se dice de diversas maneras; por ende, lejos de ser un hecho ligado al pasado remoto emerge como fenómeno vigorizado por nuevas e insospechadas formas de dominación paralelas al trasegar del tercer milenio.

Evidentemente, las características de la colonialidad en el siglo XXI no surgen por generación espontánea, sino que capitalizan, a su modo, los vestigios epistémicos y socioestructurales que constituyen la matriz colonial del poder. Se trata, entonces, de una colonialidad camaleónica que se va reinventando a sí misma desde las dinámicas contemporáneas y se hace patente en los apremiantes desafíos humanitarios, las crecientes inequidades, la amenaza bélica mundial, la pérdida de la primacía ética, la degradación medioambiental, entre otras muchas manifestaciones.

Deconstruir el relato hegemónico de las nuevas colonialidades es la apuesta sostenida de los enfoques decoloniales. Puede decirse que "la perspectiva decolonial es un enfoque comprensivo construido desde las ciencias sociales contemporáneas sobre el presupuesto de que la colonialidad es un proceso histórico inacabado que sólo ha tenido transformaciones a lo largo de tiempos y realidades, pero que nunca ha sido superado de modo definitivo" (Argüello, 2015, p. 29).

Esta resistencia epistémica, social y cultural, que se ha ido identificando también desde la contribución de Boaventura de Sousa Santos como epistemologías del Sur, abarca las variadas dimensiones de la existencia al modo de un correlato civilizacional que muestre la viabilidad y necesidad de un mundo-otro. Así se hace manifiesto en el pronunciamiento del mismo autor:

Entiendo por Epistemología del Sur el reclamo de nuevos procesos de producción y de valoración de conocimientos válidos, científicos y no científicos, y de nuevas relaciones entre diferentes tipos de conocimiento, a partir de las prácticas de las clases y grupos sociales que han sufrido de manera sistemática las injustas desigualdades y las discriminaciones causadas por el capitalismo y el colonialismo (2011, p. 35).

En esta cosmovisión de vida y de sociedad se instaura el derrotero de las pedagogías decoloniales como uno de los mecanismos más esenciales tanto al proceso de transformación de los paradigmas como a la emergencia de sus alternativas. Mientras una educación radicalmente modernizante afianza y consolida los idearios del sujeto neoliberal, un enfoque decolonial cultiva el reto de la coexistencia de lo múltiple, sin intereses de jerarquización, para hacer patente el carácter indescifrable y variopinto de la condición humana.

\footnotetext{
* Tiene un posdoctorado en Educación, Ciencias Sociales e Interculturalidad. Es profesor e investigador en la Universidad Pedagógica y Tecnológica de Colombia, UPTC-Tunja (Colombia). Sus intereses de investigación son pedagogías decoloniales, estudios biográficos, educación en derechos humanos. Correo electrónico: jaime.arguello@uptc.edu.co

** Candidata a doctora en Ciencias Políticas y Estudios Feministas en la Université de Québec à Montréal (Canadá). Es becaria Vanier y sus intereses de investigación se centran en la teoría de la descolonización y la reintegración de mujeres excombatientes.Correo electrónico: anctil_avoine.priscyll@uqam.ca
} 
De esta manera, este número convoca a repensar el vínculo entre educación y decolonialidad, el cual

... contribuye a construir un sentido amplio de pertinencia pedagógica más allá de la atención a las necesidades inmediatas del mercado profesional o de la transmisión de determinado proyecto de Nación. Expresa el retorno a la fundación ética de lo humano, de lo cósmico, de lo vital, de lo ancestral, como marco comprensivo de las educaciones de este milenio, es decir, de la pluralización de un proyecto planetario viable en la escena actual de la historia (Argüello, 2015, p. 37).

A partir del legado de la filosofía y la teología de la liberación, así como de las pedagogías críticas, el grupo de modernidad/colonialidad (Restrepo y Rojas, 2010) y las feministas decoloniales (EspinosaMiñoso, 2014; Lugones, 2008; 2010), los abordajes decoloniales de la educación han ido definiendo sus alcances y postulados. Según Cabaluz-Ducasse, las pedagogías decoloniales pueden entenderse siguiendo seis características generales: la naturaleza necesariamente política de la educación; la educación como un proceso de concientización; la importancia de los espacios populares de autoeducación desde las personas en condición marginal; el reconocimiento de las formas subalternas de conocimiento; el desarrollo de todas las facultades humanas; y el reconocimiento de los impactos culturales y sociales del colonialismo (2016, p. 76).

Por lo tanto, la decolonialidad es un horizonte particularmente amplio, diverso y fecundo para afectar las prácticas de enseñanza convencionales o las estructuras escolares repetitivas, y promueve, a su vez, espacios de autorreflexión para el cuerpo profesoral en su ejercicio pedagógico cotidiano.

De este modo, las epistemologías emergentes, que llamamos del “Sur global”, sus análisis empíricos y los métodos innovadores basados en las teorías decoloniales, permiten formas antisexistas y antirracistas de producción de conocimiento y proyectos de enseñanza. La subversión de las categorías actuales movilizadas en la construcción de conocimientos, las comprensiones culturales del mundo y su relación con los sistemas formales e informales de educación son problemáticas de alto impacto que aún resultan poco estudiadas.

Desde esta perspectiva, el número 52 de Sinéctica, Revista Electrónica de Educación, se ha propuesto explorar diferentes paisajes de conocimiento, metodologías y prácticas decoloniales en la educación como apuestas epistemológicas emergentes y como formas culturales de contestación. De esta forma, se han recolectado artículos de investigación que abordan las múltiples manifestaciones de las pedagogías decoloniales en la construcción de contra-narrativas frente a la violencia estructural, el imperialismo cultural y la producción de conocimiento hegemónico en Abya Yala y en el Sur global. De tal manera, se publican trabajos de distinta índole que expresan la multiplicidad del hecho decolonial en la educación contemporánea: experiencias curriculares propias asociadas a experiencias de escuelas decoloniales, abordajes creativos de relaciones entre colonialidad y educación con enfoques territoriales (en África, India, México o Chile), pedagogías de construcción de paz y visiones decoloniales de formación universitaria, entre otros.

Esperamos que las contribuciones de este volumen aporten a los lectores y lectoras inspiraciones para emprender sus propios diseños y prácticas de las pedagogías decoloniales tan urgentes en esta hora del mundo actual.

\section{REFERENCIAS BIBLIOGRÁFICAS}

Argüello, A. (2015). Pedagogía decolonial: trazos para la construcción de un paradigma-otro desde la educación. Correo del Maestro, vol. 226, núm. 19, pp. 28-37.

Cabaluz-Ducasse, J. F. (2016). Pedagogías críticas latinoamericanas y filosofía de la liberación: potencialidades de un diálogo teórico-político. Educación y Educadores, vol. 19, núm. 1, pp. 67-88. 
De Sousa Santos, B. (2016). Epistemologies of the South and the future. From the European South, núm. 1, pp. 17-29.

De Sousa Santos, B. (2011). Epistemologías del Sur. Utopía y Praxis Latinoamericana, vol. 16, núm. 54, pp. 17-39.

Espinosa-Miñoso, Y. (2014). Una crítica descolonial a la epistemología feminista crítica. El Cotidiano, núm. 184, pp. 7-12.

Gargallo Celentani, F. (2014). Feminismos desde Abya Yala: ideas y proposiciones de las mujeres de 607 pueblos en Nuestra América. Ciudad de México: Editorial Corte y Confección.

Lugones, M. (2010). Toward a decolonial feminism. Hypatia, vol. 25, núm. 4, pp. 742-759.

Lugones, M. (2008). Colonialidad y género. Tabula Rasa, núm. 9, pp. 73-101.

Restrepo, E. y Rojas, A. (2010). Inflexión decolonial: fuentes, conceptos y cuestionamientos. Popayán: Editorial Universidad del Cauca. 